\title{
Incerteza e dissenso: os limites institucionais da política de saneamento brasileira
}

\author{
Ana Cristina Augusto de Sousa \\ Fundação Oswaldo Cruz e IFRJ \\ Nilson do Rosário Costa \\ Fundação Oswaldo Cruz
}

O artigo demonstra que a posição de dominância das empresas estaduais de saneamento condiciona o processo decisório da política pública setorial no Brasil. O artigo descreve o processo de aprovação da Lei do Saneamento no 11.445/2007, que estabeleceu o atual regime regulatório da indústria. Conclui que o novo arranjo institucional preservou a hegemonia das empresas estaduais de saneamento. Essa hegemonia pode ser associada à baixa responsabilização das decisões de investimento e ampliação de cobertura do setor.

Palavras-chave: política de saneamento; regime regulatório; dependência de trajetória; Lei do Saneamento no 11.445/2007.

La incertidumbre y disenso: los límites institucionales de la política de saneamiento de Brasil El artículo demuestra que la posición de dominio de las empresas de saneamiento de los gobiernos provinciales contribuyeron a las limitaciones en de toma de decisiones sectorial en Brasil. El artículo describe la aprobación de la Ley de Saneamiento ํㅜ 11.445/2007, que estableció el régimen regulatorio actual de la industria. Concluye que el nuevo regime ha conservado la hegemonía de las compañías provinciales de saneamiento. Esta hegemonía se puede asociar con la falta de transparencia de las decisiones de inversión y expansión de la cobertura en la industria.

Palabras clave: políticas de saneamiento; el régimen normativo en Brasil; dependencia de la trayectoria; Ley de Sanidad de Brasil no 11.445/2007.

\section{Uncertainty and dissent: the limits of Brazilian sanitation policy}

The article demonstrates that the position of dominance of state-owned sanitation companies affects the decision-making in public policy sector in Brazil. The article describes the edition of Law of Water Supply $11.445 / 2007$ which has established the new regulatory regime for the sector. It concludes 
that the new institutional arrangement preserved the hegemony of state-owned sanitation companies. This hegemony can be associated with a low accountability of investment decisions and expansion of sector coverage.

KEYWORDS: sanitation policy; regulatory regime; path dependency; Brazil Sanitation Law $11445 / 2007$.

\section{Introdução}

Os reconhecidos efeitos sobre a qualidade de vida tornaram a política pública de saneamento essencial ao bem-estar e à saúde pública. Constata-se que o crescimento da disponibilidade dos serviços de saneamento tem sido residual nas duas últimas décadas no Brasil. A tímida expansão da oferta contrasta com o recente dinamismo da economia brasileira. O que explicaria tamanha falha institucional na provisão do item fundamental à infraestrutura do país?

Este artigo demonstra que o passado da política pública e a posição de dominância conquistada pelas empresas estaduais explicam as limitações institucionais do saneamento. A arena decisória dividida entre interesses estadualistas e municipalistas tem dificultado o consenso sobre pontos cruciais para a expansão do setor. O exercício generalizado do veto político pelos dois principais grupos de interesse mantém a incerteza decisória por décadas, afetando negativamente os mecanismos de governança e o financiamento setorial. A hipótese histórica é baseada na noção de dependência de trajetória proposta pela abordagem neoinstitucionalista, que aponta o impacto das escolhas passadas sobre as decisões públicas. Uma política pública ao iniciar uma trajetória de mudança pode sofrer a obstrução dos arranjos institucionais existentes. A dependência de trajetória explicaria a longa permanência das características institucionais da política pública de saneamento e o sucesso da obstrução sistemática pelos interesses estadualistas às inovações propostas por dois governos democráticos contemporâneos (FHC: 1995-2002; Lula: 2003-07) (Sousa e Costa, 2011).

$\mathrm{O}$ artigo analisa o veto dos estadualistas às inovações contidas na proposta original da Lei do Saneamento no 11.445/2007. Os vetos contribuíram para a modelagem de um regime regulatório inconsistente e conflitivo para o setor. De acordo com Krasner, um regime é definido por um conjunto de princípios, normas, regras e procedimentos para a tomada de decisão em torno do qual as expectativas dos atores convergem (Krasner, 1983). No setor de saneamento, o regime regulatório estabelece a regra do jogo para a atuação de empresas que agem no espaço de disputa entre governos estaduais e municipais. A formalização de um regime regulatório pode favorecer a estabilidade jurídica e a definição da titularidade, mas implica o fortalecimento da capacidade decisória das empresas estaduais ou dos governos municipais. Arretche sintetizou de modo conclusivo o significado da autonomia das empresas estaduais:

as companhias estaduais de saneamento [são] grandes e poderosas empresas, dotadas de autonomia decisória em relação a quaisquer mecanismos de supervisão e controle de suas atividades. Tal fato dificulta enormemente o exercício do poder de regulação e, portanto, a possibilidade de 
que práticas lesivas aos interesses do setor público e dos usuários possam ser coibidas. (Arretche, 1999:86)

Pretende-se demonstrar que a tramitação legislativa da Lei ํㅡㄴ 11.455/2007 polarizou os grupos de interesse em torno de questões inconciliáveis: a vitória dos interesses estadualistas resultou em uma governança setorial inconclusa e instável.

A abordagem neoinstitucionalista histórica se destaca como uma perspectiva de médio alcance para analisar processos decisórios e a formação de políticas públicas (Hall, 1987; Steinmo, 1992). Segundo Hall e Taylor (2003), o institucionalismo histórico utiliza a ideia pluralista de que o conflito entre grupos rivais por recursos está no centro da política. Porém, considera que o caminho trilhado pela estrutura política pode privilegiar alguns interesses em detrimento de outros (Hall e Taylor, 2003). Uma das principais categorias de análise do institucionalismo histórico é a dependência de trajetória: as decisões de atores específicos, sucessivas e acumuladas ao longo do tempo, deixariam legados quase irreversíveis. Em muitas situações, mas uma vez iniciadas as trajetórias institucionais, as barreiras de certos arranjos dificultariam a reversão da escolha original.

A categoria dependência de trajetória é associada à noção dos retornos crescentes. Os estudos de economia da tecnologia revelaram um terreno fértil para a exploração das condições que conduziriam a retornos crescentes. A análise de Arthur (1994) dos processos de retroalimentação positiva explica por que uma tecnologia particular pode conquistar vantagens sobre os seus competidores sem necessariamente ser a alternativa mais eficiente em longo prazo. Uma vez obtida a vantagem inicial, os efeitos de retroalimentação positiva sobre a tecnologia originalmente adotada excluem seus competidores. Segundo o autor, as configurações tecnológicas que geram retornos crescentes apresentam quatro características:

1) Alta escala: quando investimentos ou custos fixos são muito elevados, a tendência é que os atores permaneçam com a opção tecnológica ou organizacional inicial, fechando a possibilidade de alternativas;

2) Efeitos de aprendizagem: os conhecimentos acumulados na operação de sistemas complexos produzem retornos crescentes pelo uso continuado;

3) Efeitos da coordenação: o retorno ocorre quando os benefícios específicos obtidos em uma atividade se vinculam à adoção de uma mesma rede de infraestrutura tecnológica ou organizacional. A disponibilidade de uma infraestrutura incentiva que os novos investimentos sejam conectados a ela;

4) Adaptação de expectativas: os atores adaptam suas escolhas concentrando-se nas opções que podem dar mais certo.

A utilização das categorias dos retornos crescentes atingiu um grande leque de fenômenos econômicos. A aplicação ao campo da análise política trouxe também contribuições interessantes para a compreensão de processos sociais. O desenvolvimento de novas instituições 
políticas frequentemente exige altos custos de implantação, aprendizado e coordenação. Já as instituições estabelecidas permitem redução de incerteza decisória e reforçam a estabilidade (Pierson, 2004:26).

Pierson (2004:40) argumenta que há razões suficientes para afirmar que os processos políticos, assim como os econômicos são frequentemente marcados pela dinâmica dos retornos crescentes (Pierson). Esses retornos tornariam as políticas já instituídas nas sociedades modernas extraordinariamente duráveis. Os arranjos abrangentes dessas políticas configuram os incentivos e os recursos de poder dos atores sociais.

Pierson (2004) identifica duas possíveis fontes de dependência de trajetória nas políticas públicas e nos padrões de compreensão do campo social. Primeiro, a alocação de autoridade política em atores específicos pode ser uma fonte-chave de retroalimentação positiva. Para ele, quando alguns atores estão em posição de impor regras a outros, o emprego deste poder reforça a posição de poder inicial.

O segundo diz respeito às interpretações sociais de ambientes complexos quando os atores operam com alta opacidade. As identidades e interesses são aprendidos e sustentados por interações sociais construídas historicamente. O desenvolvimento de novas interpretações envolve alto custo de iniciação e aprendizagem. O entendimento dos sistemas sociais liga-se a padrões culturais compartilhados pela coletividade, que pode ser uma fonte de relativa inércia social. O desenvolvimento de normas e/ou padrões de apropriação cognitiva constitui um processo de autorreforço coletivo, que conforma as visões de mundo: uma vez estabelecidas, as interpretações políticas tendem a sobreviver independentemente das ideologias e da orientação de grupos ou partidos políticos (Pierson, 2004:38-39).

\section{A dependência de trajetória no setor de saneamento}

A análise da evolução recente da política de saneamento indica a presença de um legado político e institucional, que remonta à criação do Plano Nacional de Saneamento (Planasa) pelo governo federal em 1970. Com ele, o governo autoritário de 1964 objetivava expandir o acesso ao saneamento nas regiões industriais do país, que sofriam um considerável aumento demográfico e crise sanitária (Costa, 1998). O Fundo de Garantia por Tempo de Serviço (FGTS), criado em 1966, foi o principal recurso federal utilizado para este fim (Arretche, 1999).

Os serviços de saneamento têm a natureza de monopólio natural por conta da economia de escala, o que justificaria a presença de um produtor único em dado mercado relevante. Madeira assinala que, nesse setor, a existência de concorrência é inviável. Não é eficaz no sentido econômico nem no sentido espacial a existência de duas empresas atuando no setor de água e esgoto, com uma duplicação das redes de abastecimento e esgotamento. Dada também a estrutura do setor, a desverticalização não é recomendada (Madeira, 2010). Cabe ao governo garantir que o prestador não utilize o poder de monopólio para impor preços, restringir a qualidade e a quantidade dos serviços providos. Os serviços com características de monopólio natural são providos diretamente pelo governo ou regulados pelo Executivo. 
O Planasa incentivou a criação de 27 companhias estaduais, juridicamente constituídas como sociedades de economia mista. O mercado relevante dessas empresas foi definido por critérios políticos por compreender os territórios sob a jurisdição do Executivo municipal. Apesar de os municípios deterem a titularidade para a exploração dos serviços, as companhias assumiram os investimentos e custos fixos pertinentes à instalação e operação dos sistemas urbanos de abastecimento de água e esgotamento sanitário, assim como recrutaram e formaram a força de trabalho do setor.

A sustentação econômica dessas empresas foi obtida por via tarifária, com base no mecanismo financeiro dos subsídios cruzados. Por esse mecanismo, estratos populacionais mais ricos subsidiaram a expansão dos serviços para os estratos mais pobres, via tarifação diferenciada.

Para obter a adesão dos municípios resistentes, o governo federal vinculou o acesso aos novos recursos do FGTS à concessão dos direitos de exploração para as companhias estaduais. Somente municípios com independência fiscal resistiram à pressão do governo central. A centralização do poder na União pelo regime autoritário de 1964 já havia minado a capacidade de reação dos municípios (Draibe, 1989).

As companhias estaduais ganharam amplo poder de alocação, tornando-se inteiramente responsáveis pela definição de prioridades, tecnologias e estratégias de expansão. Esse foi o início de uma relação assimétrica e conflitiva entre estados e municípios: a transferência da gestão verticalizada para os primeiros passou pela submissão política dos últimos.

$\mathrm{O}$ arranjo criado pelo Planasa permitiu às companhias estaduais o protagonismo institucional na prestação dos serviços de abastecimento de água e esgotamento sanitário no Brasil. Além de exercerem nas grandes cidades as funções de monopólio natural, elas reuniram várias características favoráveis à permanência. Em nível tecnológico, elas operaram serviços de alta escala, com altos efeitos de aprendizagem, coordenação e adaptação. Em nível político, elas contaram com uma forte alocação de poder nos estados, consolidando a cultura de prestação neste nível de governo. Essa situação não se alteraria com o esgotamento do Planasa e a redemocratização do país na década de 1980.

A Constituição de 1988 revigorou o papel dos municípios no pacto federativo, ratificando a titularidade sobre a prestação de serviços urbanos de interesse local. Num contexto de vencimento dos contratos firmados à época do Planasa, a decisão constitucional fortaleceu a decisão de retomar os serviços de saneamento por parte dos municípios insatisfeitos com a posição de dominância territorial das empresas estaduais. Em 1984 os municípios já tinham se coligado na Associação Nacional dos Serviços Municipais de Saneamento (Assemae). Fundada com o objetivo de fortalecer a capacidade técnica, administrativa e financeira dos serviços municipais de saneamento, a Assemae tornou-se a porta-voz dos interesses municipalistas do saneamento.

A reação dos estados às iniciativas municipalistas foi igualmente vigorosa: em 1985, as empresas estaduais fundaram a Associação das Empresas de Saneamento Básico Estaduais (Aesbe) com o objetivo de defender os interesses e organizar a ação coletiva diante do desmonte do Planasa. A decisão aguçou, no contexto da transição democrática, a histórica rivali- 
dade entre municipalistas e estadualistas. Reunindo 25 empresas estaduais, a Aesbe tornou-se o principal órgão de representação e intermediação de interesses, atuando abertamente na definição da agenda setorial.

Nos anos 1990, a acirrada disputa pela titularidade sobre a prestação levou alguns municípios e estados à Corte Constitucional (Supremo Tribunal Federal — STF). Nela tramitam ações questionando a constitucionalidade de leis estaduais que vinculam a prestação dos serviços de saneamento nas regiões metropolitanas à competência estadual. A delegação de decisões setoriais dessa importância à Corte Constitucional revela que a ferida da decisão autoritária ainda não foi fechada, assim como o alto grau de dissenso entre os grupos de interesse do setor a respeito do arranjo institucional.

Em fins da década de 1990, as iniciativas do governo federal, por sua vez, concentraram-se na liberalização da prestação desses serviços (Brasil, PLS 266/1996 e PL 4.147/2001), em atendimento aos compromissos formalizados com o FMI em 1999 (Brasil, 1999). Para tanto, incentivou os governadores de estado a privatizarem empresas de saneamento. Apesar da concordância de alguns governadores, as privatizações não foram adiante principalmente pelo veto dos grupos com interesses diretos e indiretos afetados pela mudança no mecanismo de governança.

A aglutinação desses grupos para vetar essa iniciativa se deu em torno da defesa da governança estatal vertical, prevalente desde a criação do Planasa. Os principais beneficiários diretos dessa governança tinham sido os setores ligados às atividades das empresas estaduais de saneamento: Executivo estadual, secretários de governo, dirigentes, funcionários e fornecedores.

$\mathrm{O}$ veto à privatização foi conduzido principalmente por grupos municipalistas, unidos sob a Frente Nacional pelo Saneamento Ambiental (FNSA). A liderança de grupos municipalistas deveu-se ao fato de a proposta do governo estabelecer como condição para a privatização a estadualização da titularidade. Os municípios perderiam totalmente a competência sobre a prestação desses serviços, eliminando o poder de intervenção e concessão. Em defesa da governança estatal, formou-se uma precária e fugaz coalizão de municipalistas e estadualistas. Os grupos de interesse suspenderam as divergências quanto à titularidade da prestação, já transferida para outra arena decisória (STF), e conseguiram derrubar a proposta de privatização das empresas estaduais.

Apesar da liderança dos grupos municipalistas sobre o processo de veto à privatização, não se observou, entretanto, um avanço expressivo nas tratativas visando a municipalização da prestação dos serviços de saneamento. As companhias estaduais continuariam impassíveis na preservação do domínio da operação física e condução institucional herdadas do Planasa.

Em 2007, quando foi aprovada a Lei do Saneamento, as 26 empresas estaduais de saneamento originalmente criadas nos anos 1970 abasteceram com água mais de 73\% e coletaram o esgoto de aproximadamente 18\% dos municípios brasileiros (Brasil, 2007a). Essa situação reiterava o papel hegemônico exercido pelas empresas estaduais no abastecimento de água e no esgotamento sanitário. 


\section{0 novo regime regulatório do saneamento no Brasil: veto e dissenso}

A emergência do governo Lula em 2003 se deu em um contexto em que a privatização do saneamento já não constituía mais uma ameaça, nem mesmo uma necessidade para o equilíbrio das contas públicas e sinalização ao mercado financeiro. Primeiramente, porque o custo do ajuste fiscal já havia sido alcançado com a privatização dos bancos estaduais e a contenção das despesas financeiras pela Lei de Responsabilidade Fiscal de 2000. As empresas estaduais de saneamento que não tiveram que abrir o capital continuaram a operar, como de costume, em caixa único com o orçamento do Executivo estadual.

Ademais, os grupos que vetaram a privatização do saneamento no governo Cardoso serviram de forte base de apoio para a eleição do governo Lula em 2003. A coalizão vencedora no governo federal centralizou a campanha eleitoral de 2002 na crítica contundente à privatização e na defesa da provisão estatal direta dos serviços.

Essa convergência política se refletiu na alocação de seus mais importantes dirigentes da FNSA em postos-chave do setor no novo governo. Várias lideranças foram nomeadas para administração federal em diferentes ministérios. Para a secretaria de saneamento ambiental, em especial, foi nomeado o engenheiro Abelardo Oliveira Filho, presidente da FNSA até 2002. A expectativa era que, uma vez no governo, declaradamente contrário à privatização, esses atores tornariam possível um regime regulatório fundado na gestão democrática e na universalização do saneamento. Nesse contexto, o setor iniciou, sem dúvida, em nível federal, um intenso processo de reestruturação institucional.

Em resposta à demanda histórica dos movimentos sociais ligados à questão urbana, o Executivo federal criou, em 2003, o Ministério das Cidades (MC). Com a proposta de integrar as políticas ligadas ao desenvolvimento urbano, o MC se tornou o responsável pelas políticas de habitação, saneamento ambiental, transporte urbano e trânsito. A criação do Grupo de Trabalho Interministerial (GTI) visou instituir um novo regime regulatório para o saneamento por meio de consultas e audiências públicas.

Participaram da configuração do novo regime regulatório 320 mil pessoas em 3.457 conferências municipais, 27 conferências estaduais e no Distrito Federal, assim como na Conferência Nacional das Cidades de 2003 (Projeto de Lei — PL — oㅜ 5.296/2005) (Brasil, 2005a). Em meio às reuniões do GTI, foram realizados ainda, com o apoio das entidades da Frente, 10 seminários regionais e um nacional para o aprimoramento do projeto. Uma vez finalizado, o regime regulatório foi submetido a uma consulta pública (via internet) e à aprovação dos Conselhos Nacionais de Saúde e das Cidades. Tendo sido aprovado nessas instâncias, o PL no 5.296/2005 foi encaminhado pela Casa Civil da Presidência à câmara dos Deputados.

Definiu-se como princípio que os serviços de saneamento seriam prestados sob o regime de monopólios estatal (Brasil, 2003). O PL no 5.296/2005 contemplava ainda a titularidade municipal sobre os serviços de interesse local; uma concepção abrangente de saneamento abastecimento de água, esgotamento sanitário, drenagem urbana e resíduos sólidos - e a criação de um Sistema Nacional de Saneamento (Sisnasa), que subordinaria a ação dos pres- 
tadores a normas e princípios federais. Propunha ademais a criação das agências reguladoras e a obrigação dos planos municipais e estaduais de saneamento.

O projeto previa também a instituição de fundos municipais e estaduais para a universalização do acesso, em vez de subsídios cruzados. Na questão do controle social, propunha-se atribuir aos órgãos colegiados competências na formulação, implantação e fiscalização dos serviços (Brasil, 2003; 2006).

Na câmara, o projeto de lei foi alvo único das 862 emendas. Segundo a FNSA, as emendas pretendiam uma completa modificação da proposta governista, com o objetivo de atender às demandas estadualistas (FNSA, 2005a, 2006a, 2006d). O artigo sobre titularidade foi alvo de 63 emendas. Numa verdadeira queda de braço, governo e opositores estadualistas não chegaram ao consenso. A FNSA, que antes unificara municipalistas e estadualistas no veto à privatização, assumiu a defesa intransigente do projeto do Executivo federal, apoiada pelas associações de Prefeitos (FNSA, 2005a, 2006a, 2006b).

Enquanto a disputa se desenvolvia na Câmara dos Deputados, outro projeto de lei favorável às empresas estaduais tramitou no Senado. Formulado pelo Fórum dos Secretários Estaduais de Saneamento e pela Aesbe, o Projeto de Lei do Senado (PLS) no 155/2005 foi aprovado por unanimidade em duas comissões e tramitava em fase terminativa na comissão de infraestrutura. Contemplava as demandas das empresas estaduais nos seguintes itens: restringia a abrangência dos serviços de saneamento ao abastecimento de água e esgotamento sanitário, protegia o investimento já realizado pelas empresas - minimizando a incerteza jurídica diante da disputa por titularidade — e incentivava a sustentabilidade econômica da prestação dos serviços. Não previa medidas de efetiva proteção ao consumidor, nem instrumentos de controle social, permitindo inclusive que os planos de saneamento pudessem ser elaborados pelas próprias prestadoras do serviço. Além disso, não tocava na questão do financiamento e nem na criação de um Sistema Nacional de Saneamento (Brasil, 2005b).

Este projeto contrariava os pontos centrais da proposta do governo Lula e impunha uma derrota brutal às pretensões dos municipalistas. Ademais, sua tramitação encontrava-se mais avançada que o PL nº 5.296/2005 proposto pela Casa Civil. Diante do risco da derrota, a FNSA pressionou pela criação de uma Comissão Mista - de deputados e senadores — para a análise e fusão dos dois projetos de lei (FNSA, 2006d). A solução dos principais pontos de dissenso - a abrangência dos serviços, a titularidade, o sistema nacional de saneamento, o financiamento por fundo setorial e o controle social — foi adiada e transferida para uma nova arena decisória (Brasil, 2003; 2006:33-34; FNSA, 2005a, 2005b, 2006a, b, c).

A precária aliança que outrora uniu até 2002 os dois grupos de interesse contra a privatização se esgotou completamente em um novo cenário em que a governança estatal não era mais objeto de contestação pelo Executivo federal. Dessa forma, as históricas divergências, antes reprimidas em nome da luta contra a privatização, realimentaram o conflito federativo em relação à política pública do saneamento. Na nova arena decisória, os movimentos sociais se alinharam à FNSA e as empresas privadas aos grupos estadualistas.

O quadro 1 mostra a posição dos dois principais grupos de interesse em relação aos principais pontos de inovação institucional propostos para o setor: 
Quadro 1

Principais pontos de dissenso entre os municipalistas e os estadualistas na tramitação da Lei do Saneamento de 2007

\begin{tabular}{|ccc|}
\hline ITENS DE DISSENSO & AGENDA ESTADUALISTA & AGENDA MUNICIPALISTA \\
\hline Titularidade & Estadual nas regiões metropolitanas & Municipal \\
Abrangência dos serviços & Água e esgoto & $\begin{array}{c}\text { Água, esgoto, drenagem urbana e } \\
\text { resíduos sólidos }\end{array}$ \\
Sisnasa & Contrário & Favorável \\
Financiamento da universalização & Subsídios cruzados & Fundos federativos \\
Órgãos colegiados de controle social & Facultativos e estritamente & Obrigatórios e fortalecidos em todos os \\
& consultivos & níveis da federação \\
\hline
\end{tabular}

Fonte: Brasil (2003). Elaborado pelos autores.

A maioria de parlamentares da Comissão Mista não apoiava as pretensões da FNSA, o que a deixou numa situação desfavorável. Ainda assim, a FNSA com o Ministério das Cidades pressionaram por uma proposta substitutiva ao PLS no 155/2005 (FNSA, 2005b, 2006a, 2006d). O projeto substitutivo do relator Julio Lopes (PP/RJ) foi a alternativa: aprovado na Comissão Mista e, em seguida, no Senado. Sob o nome de PLS no 219/2006, o projeto seguiu para a Câmara dos Deputados para ser submetido ao plenário em regime especial de tramitação, ainda naquela legislatura. Renomeado de PL nº 7.361/2006, o projeto foi finalmente aprovado em dezembro de 2006, pouco mais de um ano depois de ser apresentado. Recebeu a sanção do presidente Lula em 5 de janeiro de 2007, já durante o segundo mandato.

A construção de consenso foi o principal desafio da nova Lei de Saneamento de 2007. Diante da força dos grupos estadualistas, a FNSA abdicou das principais bandeiras.

Com a indefinição da titularidade na lei, as empresas estaduais conseguiram prolongar a dominância na prestação dos serviços de saneamento à espera da decisão do STF. O impasse jurídico ainda vigente aumenta os custos - políticos e judiciais - para os municípios que decidam rescindir os contratos herdados do Planasa.

Na nova lei, a concepção abrangente dos serviços de saneamento defendida pelos municipalistas foi preservada (Lei no 11.445/2007, art. 3느, I). É preciso destacar, no entanto, que, apesar de inicialmente ter se configurado como uma questão de divergência entre grupos municipalistas e estadualistas, a concepção ampliada de saneamento não afetava a posição estabelecida das empresas estaduais. Isso porque os serviços de drenagem de águas pluviais e de resíduos sólidos são tradicionalmente providos pelos municípios, não atingindo assim as atividades daquelas empresas.

Os grupos estadualistas vetaram, entretanto, a criação do Sisnasa, que condicionaria o acesso aos recursos da União pelos prestadores estabelecidos às decisões do Ministério das Cidades e a órgãos colegiados de âmbito federal (Conferência Nacional e Conselho das Cidades), estadual (Conferências e Conselhos Estaduais das Cidades) e municipal (Conferências 
e Conselhos da Cidade). Este era um ponto de veto para os grupos estadualistas, pois representava a subordinação dos prestadores às decisões de uma Política Nacional de Saneamento, interpretada como um ataque à autonomia federativa.

A proposta municipalista de substituição do mecanismo de subsídios cruzados por meio de tarifas regionais pela implantação de fundos federativos para o financiamento da universalização foi igualmente vetada. Segundo os grupos estadualistas, a substituição inviabilizaria a prestação regionalizada dos serviços. Os subsídios cruzados então permaneceram e a implantação dos fundos tornou-se facultativa, ao invés de obrigatória, como propunha o governo (Lei no 11.445/2007, art. 13).

Por fim, os grupos estadualistas conseguiram ainda reduzir o escopo da proteção dedicada ao usuário e eliminar da Lei nํㅜ11.445/2007 a obrigatoriedade dos órgãos colegiados em todos os níveis federativos, tornando a sua existência facultativa e estritamente consultiva (Lei no 11.445/2007, art. 47). A precarização do papel dos órgãos colegiados inibe concretamente o controle social sobre as ações e decisões dessas empresas. Evitou-se a interferência externa sobre a prestação, especialmente por parte dos usuários. O quadro 2 resume as principais demandas e vetos estadualistas contempladas pela Lei ํํำ 11.445/2007.

Quadro 2

Propostas contempladas ou vetadas na Lei do Saneamento e seus beneficiários

\begin{tabular}{|ccc|}
\hline $\begin{array}{c}\text { PROPOSTA ORIGINAL DO GOVERNO } \\
\text { APOIADA PELA FNSA } \\
\text { (PL no 5.296/2003) }\end{array}$ & $\begin{array}{c}\text { LEI APROVADA } \\
\text { (Lei no } \mathbf{1 1 . 4 4 5 / 2 0 0 7 )}\end{array}$ & PEINCIPAL \\
BENEICIÁRIO
\end{tabular}

Fontes: Brasil (2007b). Elaborado pelos autores.

\section{Conclusão}

A utilização da categoria dependência de trajetória possibilitou identificar a matriz histórica da inércia da política pública de saneamento no Brasil. A decisão passada de estadualização do setor produziu retornos institucionais positivos que retroalimentam as escolhas públicas contemporâneas.

Os mecanismos de coordenação e adaptação criados pelas empresas estaduais de saneamento geraram, sobretudo, reforços políticos não negligenciáveis para a preservação da 
estrutura institucional montada pelo Planasa. Por décadas, as instituições formais produzidas pelo arranjo estadualista têm criado extensos constrangimentos ao comportamento dos atores do setor, moldando seus incentivos e recursos de poder. A reversão do curso da escolha inicial do Planasa parece implicar altos custos de ruptura, especialmente para o governo federal.

Para Pierson (2004:37), o uso contínuo de poder para consolidar a vantagem política conquistada produz condições brutalmente assimétricas nas situações críticas de conflito por interesses. O processo de estadualização da prestação dos serviços por meio das companhias estaduais nos anos 1970 configurou uma relação política autoritária entre municípios e estados, colocando os segundos na posição de impor regras aos primeiros. A capacidade de coordenação do governo federal tem sido igualmente frágil por não conseguir superar o impasse decisório setorial ou subordinar as preferências dos governos estaduais às escolhas do governo federal ou municipal. As evidências deste artigo sugerem que sejam atenuadas as conclusões de Arretche de começo dos anos 2000 sobre a política pública contemporânea para o saneamento do Brasil (Arretche, 2002). Ao contrário do que diz a autora, no atual contexto, o poder de obstrução dos governos subnacionais no federalismo brasileiro tem representado um ponto de veto intransponível à implantação da agenda de reforma do governo federal na política de saneamento. Este artigo demonstra que a presença de legados institucionais potencializou o poder de veto dos interesses estaduais à implantação do regime regulatório municipalista para o saneamento proposto pelo governo Lula (2003-10).

Neste artigo demonstrou-se que a proposta do governo Lula e da coalização municipalista para o saneamento alteraria o modelo de prestação dominante no Brasil. O reconhecimento da titularidade dos municípios, a instituição de fundos de universalização, do Sistema Nacional de Saneamento (Sisnasa) e o fortalecimento de instâncias de controle social desafiariam o papel dominante das empresas estaduais. Entretanto, as empresas estaduais impuseram o veto generalizado à agenda inovadora e garantiram a permanência do arranjo histórico do setor. O sucesso do veto pelas empresas estadualistas contradiz, portanto, a tese de que na política de saneamento - a exemplo da educação fundamental, habitação e saúde — o governo federal teria sido bem-sucedido na imposição de suas preferências no contexto da Nova Democracia (Arretche, 2002). Em relação ao regime regulatório do saneamento, o governo federal ficou imobilizado diante do poder de veto dos interesses dos governos estaduais.

Apesar da vitória expressiva no Congresso, contra a orientação do governo federal, o ônus à reputação e credibilidade das empresas estaduais de saneamento tem sido nulo. Elas mantiveram a subordinação aos Executivos estaduais e o livre acesso aos recursos federais. Isto indica que, para obter a adesão dos governos estaduais à política de investimento que envolve relações intergovernamentais, o Executivo federal tem preservado as preferências das empresas estaduais, tornando o objetivo da coordenação da política de infraestrutura no saneamento cada vez mais improvável. Os investimentos com recursos públicos subsidiados e onerosos continuam sendo realizados predominantemente em municípios com superavit de serviços de saneamento em função das decisões das empresas estaduais, que detêm capacidade institucional de elaboração de projeto e porte financeiro para cumprimento das regras para acesso aos recursos federais (Brasil, 2011). 
Cabe assinalar que a proposta de criação do fundo setorial retiraria das empresas estaduais a independência alocativa, transferindo a decisão para uma arena povoada por múltiplos atores. A sobrevivência do atual arranjo institucional não tem, de qualquer modo, respondido de modo efetivo às exigências sociais do país.

\section{Referências}

ARRETCHE, Marta T. S. Federalismo e relações intergovernamentais no Brasil: A reforma de programas sociais. Dados - Revista de Ciências Sociais, Rio de Janeiro, v. 45, n. 3, p. 431-458, 2002.

ARRETCHE, Marta T. S. Política Nacional de Saneamento: A reestruturação das companhias estaduais. In: Temas especiais — Infraestrutura. Perspectivas de reorganização. Brasília: Ipea, 1999.

ARTHUR, Brian W. Increasing returns and path-dependence in the economy. Ann Arbor: University of Michigan Press, 1994.

AVELAR, Lúcia; CINTRA, Antônio O. (Org.). O sistema político brasileiro. São Paulo: Ed. Unesp, 2004.

BRASIL. Câmara do Senado. Projeto de Lei do Senado n. 155/05 de 11/05/2005b. Estabelece diretrizes nacionais para o saneamento básico e dá outras providências.

BRASIL. Câmara do Senado. Projeto de Lei do Senado n. 219 de 11/07/2006. Estabelece diretrizes nacionais para o saneamento básico e dá outras providências.

BRASIL. Câmara dos Deputados. Projeto de Lei 1.144/03 de 29/05/2003 e apensos. Institui as diretrizes para os serviços públicos de saneamento básico e a política nacional de saneamento básico (PNS).

BRASIL. Câmara dos Deputados. Projeto de Lei 5.296 de 23/05/2005a. Institui as diretrizes para os serviços públicos de saneamento básico e a política nacional de saneamento básico (PNS).

BRASIL. Lei 11.445 de 05/01/2007. Estabelece as diretrizes nacionais para o saneamento básico. 2007b.

BRASIL. Ministério das Cidades. Panorama do saneamento. Brasília, 2011. v. 3.

BRASIL. Ministério das Cidades. Resoluções da I Conferência das Cidades (23 a 26 de outubro de 2003). Brasília, 2003.

BRASIL. Ministério das Cidades. Sistema Nacional de Informação em Saneamento (SNIS), 2007a.

BRASIL/FMI. Memorando de política econômica de 08/03/1999. Disponível em: <www.receita. fazenda.gov.br>. Acesso em: 20 mar. 2007.

COSTA, Nilson R. Política pública, justiça distributiva e inovação: saúde e saneamento na agenda social. São Paulo: Hucitec, 1998. 
DRAIBE, Sonia M. Welfare State no Brasil: características e perspectivas. Ciências Sociais Hoje, São Paulo, n. 26, p. 13-61, 1989.

FNSA. Avaliação do PL 7.361/06. 2006d.

FNSA. Avaliação do PLS 219/06. 2006c.

FNSA. Manifesto aos deputados federais e senadores: Por uma política de saneamento ambiental e democrática que respeite a cidadania e o pacto federativo: os problemas do relatório do dep. Júlio Lopes ao PL 1.144/03 e demais projetos de saneamento avaliados pela Comissão Especial da CDU. 2006b.

FNSA. Manifesto de repúdio. 2006a.

FNSA. Nota oficial sobre o PLS 155/05 do senador Gerson Camata. Brasília, 22 jun. 2005b.

FNSA. Resolução da FNSA sobre o PL 5.296/05. Brasília, 22 jun. 2005a.

HALL, Peter A. The politics of State intervention in Britain and France. Nova York: Oxford University Press, 1987.

HALL, Peter A.; TAYLOR, Rosemary C. R. As três versões do neoinstitucionalismo. Lua Nova, São Paulo, n. 58, p. 193-223, 2003.

KRASNER, Stephen D. International regimes. Ithaca: Cornell University Press, 1983.

MADEIRA, Rodrigo F. O setor de saneamento básico no Brasil e as implicações do Marco Regulatório para a universalização do acesso. Revista do BNDES, n. 33, p.123-154, jun. 2010.

PIERSON, Paul. Politics in time: history, institutions and social analysis. Nova Jersey: Princeton University Press, 2004.

SOUSA, Ana Cristina A.; COSTA, Nilson R. A crise do setor de saneamento no Brasil: uma revisão bibliográfica. $B I B$, n. 66, p. 5-25, 2008.

SOUSA, Ana Cristina A.; COSTA, Nilson R. Ação coletiva e veto em política pública: o caso do saneamento no Brasil (1998-2002). Ciência e Saúde Coletiva, v. 16, n. 8, p. 3541-3552, 2011.

STEINMO, Sven et al. Structuring politics: historical institutionalism in comparative perspective. Cambridge: Cambridge University, 1992.

Ana Cristina Augusto de Sousa é pesquisadora do Departamento de Ciências Sociais da Escola Nacional de Saúde Pública Sergio Arouca/Fundação Oswaldo Cruz (ENSP/Fiocruz) e professora de História do Instituto Federal de Educação, Ciência e Tecnologia do Rio de Janeiro (IFRJ). E-mail: crisantemo_s@ bol.com.br.

Nilson do Rosário Costa é pesquisador titular do Departamento de Ciências Sociais da Escola Nacional de Saúde Pública Sergio Arouca/Fundação Oswaldo Cruz (ENSP/Fiocruz). E-mail: nilsondorosario@ terra.com.br. 
